\title{
O CORPO FEMININO E OS LUGARES DE SEUL: ESPAÇO, GÊNERO E IDENTIDADE NO ROMANCE COREANO THE MOTHER'S STAKE (EOMMANUI MALTTUK), DE PARK WAN SEO.
}

\author{
THE FEMALE BODY AND THE PLACES OF SEOUL: SPACE, \\ GENDER, AND IDENTITY IN KOREAN NOVEL THE \\ MOTHER'S STAKE (EOMMANUI MALTTUK), BY PARK WAN \\ SEO.
}

Melissa Rubio dos Santos Autor ${ }^{1}$

\begin{abstract}
RESUMO: O presente artigo tem como objetivo explorar a questão do espaço na Literatura Coreana a partir da obra The Mother's Stake (Eommanui Malttuk, 1980) de Park Wan Seo. O estudo propõe uma reflexão acerca dos trânsitos imagéticos no/pelo espaço, como também de destacar o papel desempenhado pela literatura de autoria feminina no âmbito literário contemporâneo da Coreia do Sul. A pesquisa tem as seguintes perguntas norteadoras: Como é o corpo feminino representado na narrativa? Qual é o papel que o espaço desempenha na narrativa? Quais são as linhas traçadas pelo corpo feminino no espaço nas cidades de Incheon e Seul? Como a escritora Park Wan Seo representa a autoria feminina no âmbito da Literatura Coreana Contemporânea? Para a realização do estudo, o referencial teórico utilizado se centra na obra da teórica Dorren Massey (Pelo Espaço, 2008).
\end{abstract}

PALAVRAS-CHAVE: Literatura Comparada, Literatura Coreana, Gênero, Espaço, Imagem.

\begin{abstract}
This paper aims to explore the issue of space in Korean Literature from novel The Mother's Stake (Eommanui Malttuk, 1980) by Park Wan Seo. The study proposes a flection on imagistic transits in / through space, as well as highlighting the role played by Women's in the Korean Contemporary literary sphere. The research has the following driving questions: How female body isrepresented in the narrative? What is the role that Space plays in the narrative? What are the lines drawn by the female body in space in the cities of Incheon and Seoul? How does writer Park Wan Seo represent Women's literature in the context of Korean Contemporary Literature? To conduct the research, the theoretical reference used is focused on the work of Dorren Massey (For Space, 2008).
\end{abstract}

KEY WORDS: Comparative Literature, Korean Literature, Gender Studies, Space, Image.

1 Doutoranda em Estudos Literários, Teoria, Crítica e Comparatismo na Universidade Federal do Rio Grande do Sul. Mestre em Estudos Literários - Especialidade Literatura Comparada pela Universidade Federal do Rio Grande do Sul. 


\section{Introdução}

Viajar entre lugares é mover-se entre coleções de trajetórias e reinserir-se naquelas com as quais nos relacionamos. Doreen Massey (2008, p. 190)

Para o estudo dos trânsitos imagéticos no/pelo espaço na obra The Mother's Stake (Eommanui Malttuk, 1980) de Park Wan Seo, considero importante estabelecer dois focos. Primeiramente, pretendo apresentar uma análise do espaço a partir da minha experiência na Coreia do Sul, tendo como foco a cidade de Seul, sendo esta escrita inspirada pelas reflexões sobre o espaço e lugar da obra de Dorren Massey (Pelo Espaço), e, portanto, construindo um texto analítico crítico. Já o segundo momento do artigo consiste na leitura do romance The Mother's Stake (1980) de Park Wan Seo e no detalhamento dos pontos fulcrais para a problematização do espaço na obra. Através do estudo do romance de Park, pretendo levantar questões acerca da questão do espaço na literatura de autoria feminina e, dessa forma, propor uma diferenciada leitura do corpus literário contemporâneo da Coreia do Sul.

Cabe apresentar, ainda que brevemente, a escritora coreana Park Wan Seo. Considerada como a mais importante escritora coreana, Park recebeu diversos prêmios no meio acadêmico da Coreia do $\mathrm{Sul}^{2}$. Ela teve intensa produção literária ao longo de três décadas, tendo publicado 20 romances e 100 contos. $^{3}$ Presenciou a Guerra da Coreia e também as transformações sociais e políticas da Coreia ao longo das últimas décadas. Park Wan Seo começou a publicar as suas obras tardiamente, tendo a sua estreia no cenário literário coreano com o livro The Naked Tree (Namok) em 1970, obra que trata da condição feminina na Coreia do pós-guerra. A autora também relata em suas obras as profundas e rápidas mudanças que a Coreia tem sofrido desde a Guerra da Coreia e sua consequente rápida

\footnotetext{
${ }^{2}$ Recebeu os prêmios Korean National Literature Award (한국문학작가상) em 1980, Yi Sang Literary Award em 1981, Republic of Korea Literature Prize (대한민국문학상 em 1990, Hyundae Munhak Award em 1993, Dong-in Literary Award em 1994, Daesan Literary Awards em 1997, The Manhae Prize for Literature por The Loneliness of Youa collection of short stories, Ho-am Prize in the Arts em 2006. Order of Cultural Merit em 2011.

${ }^{3}$ Obras de Park Wan Seo: The Naked Tree (Namok, 1970), Year of Famine in the City (도시의 흉년, 1979), The Beginning of Days Lived (Sara-inneun, Nal-ui Sijak, 1980), Three Days in That Autumn (그 가을의 사흘동안, 1980), Mother's Garden (엄마의 말뚝, 1982), Mother's Stake (Eommanui Malttuk, 1982), Warm Was the Winter That Year (Geuhae Gyeoul-eun Ttatteuthaenne, 1983), The Woman Standing (Seoinneun Yoja, 1985), Illusion (Mimang, 1990), My Beautiful Neighbor (Na-ui Areumdaun Iut, 1991), The Dreaming Incubator (Kkumkkuneun Incubator, 1993), Such a Lonely You (Neomuna Sseulsseurhan Dangsin, 1999), A Very Old Joke (Silcheonmunhak, 2000), Who Ate up All the Sing-a (Woongjin, 2002), Identical Apartments (In: The Future of Silence Fiction By Korean Women, 2016).
} 
industrialização. Desde o início do século XX, o país tem sofrido transformações culturais que desencadearam, por vezes em mudanças nos padrões familiares e sociais ou em impasses e bloqueios na transformação devido à força e influência de valores tradicionais e seculares da cultura coreana. De acordo com Stephen Epstein, tradutor da obra Who Ate up All the Sing-a (Woongjin, 2002), de Park Wan Seo para o inglês, a autora emprega em suas obras uma peculiar estratégia narrativa: "what may seem initially to be a story with public concerns then turns to center upon family relationships or vice-versa, as personal drama suddenly takes on wider implications".

Ao longo dos últimos anos tenho realizado a minha pesquisa acadêmica sobre a Coreia do Sul como aluna e pesquisadora da Literatura Comparada do Instituto de Letras da UFRGS. Devido ao fato de eu ser uma pesquisadora de país tão distante, os deslocamentos protagonizados por mim entre Brasil e Coreia do Sul foram responsáveis pela minha inquietação sobre trânsitos de significantes, afetos e relações com as novas cidades. E, dessa forma, surgiu a demanda para refletir acerca do espaço. Eu já não podia mais pensar sobre os meus objetos literários sem considerar as relações estabelecidas entre o eu-sujeito pesquisadora e os lugares que eu visitava, observava e experenciava na Coreia. Portanto, para a escrita deste texto, tenho como base teórica a obra Pelo Espaço (2008), de Doreen Massey. Portanto, associo os caminhos que percorri nos diversos bairros e nas cidades coreanas como lugares com os quais eu pude me relacionar. Uma vez que, conforme Massey afirma, "Viajar entre lugares é mover-se entre coleções de trajetórias e reinserir-se naquelas com as quais nos relacionamos" (2008, p.190). Transitar entre lugares seria um experenciar de "eventualidades espaço-temporais" (MASSEY, 2008, p.191). Sendo assim, eu gostaria de abordar, as relações estabelecidas por mim com a cidade de Seul.

\section{Olhar para a cidade de Seul: O Rio Han e os portões de Seul}

Residir na capital da Coreia do Sul, Seul, proporciona múltiplas experiências-seja por ser a cidade sobre a qual mais se ouve relatos históricos, o que faz povoar o imaginário antes mesmo de se estar nela; seja por ser a cidade em que há mais trânsitos culturais pelos fluxos imigratórios e turísticos, proporcionando o multiculturalismo (ou presença de outras culturas). Ao longo dos dias que vivi em Seul eu experenciava os reflexos de uma metrópole de efusivos movimentos com seus silêncios/vozes, olhares fugidios e múltiplos significantes.

No meu olhar, dois elementos se destacam no processo de construção do que chamo de 'constelação espacial de Seul': o Rio Han 한강(Han Gang) e os Portões de Seul. Partindo da 


\section{critica | literatura | artes \\ jangada}

concepção de espaço como "uma simultaneidade de estórias-até-então", cabe refletir como são construídos os lugares. Considerando que o espaço não está isolado, uma vez que "espaço e tempo juntos" resultam em múltiplo devir. De acordo com Massey, "o 'aqui' é nada mais (e nada menos) do que o nosso encontro e o que é feito dele. É, irremediavelmente, aqui e agora. Não será o mesmo 'aqui' quando não for mais agora" (2008, p. 201). Logo, para pensar o espaço dentro daquela realidade, eu deveria colocar em cena as estórias-até-então como também ler o espaço-tempo, ou seja, interpretar o espaço em minha própria temporalidade.

O Rio Han /한강(Han Gang) é o elementro nodal da cidade de Seul. Não há como pensar a imagem de qualquer mapa de Seul sem a presença do Rio $\mathrm{Han}^{4}$. Os mais diversos significados são atribuídos a este rio, assim como aos parques em sua encosta que corta a cidade de Seul. Entretanto, os significados do Rio Han vão além dos comuns ou recorrentes siginificados fonte de recursos naturais e beleza natural. Ao percorrer a cidade, pude constatar novos elementos para leituras do lugar Rio Han, tais como o contraste entre a natureza e o progresso da modernidade acelerada da Coreia, o lugar de repouso e diversão proporcionado nos parques na encosta do rio ${ }^{5}$, os deslocamentos proporcionados pela navegação, o lugar de passagem para aqueles que estão no metrô em uma linha que cruza o Rio Han ${ }^{6}$, o lugar de conforto nas luzes silenciosas na noite ${ }^{7}$ ou até mesmo ser o conhecido lugar em que os coreanos silenciam eternamente a tristeza, o que motivou uma campanha governamental contra o suicídio nas pontes do Rio $\operatorname{Han}^{8}$.

Imagem 01: Rio Han. (Fonte: Visit Seou)

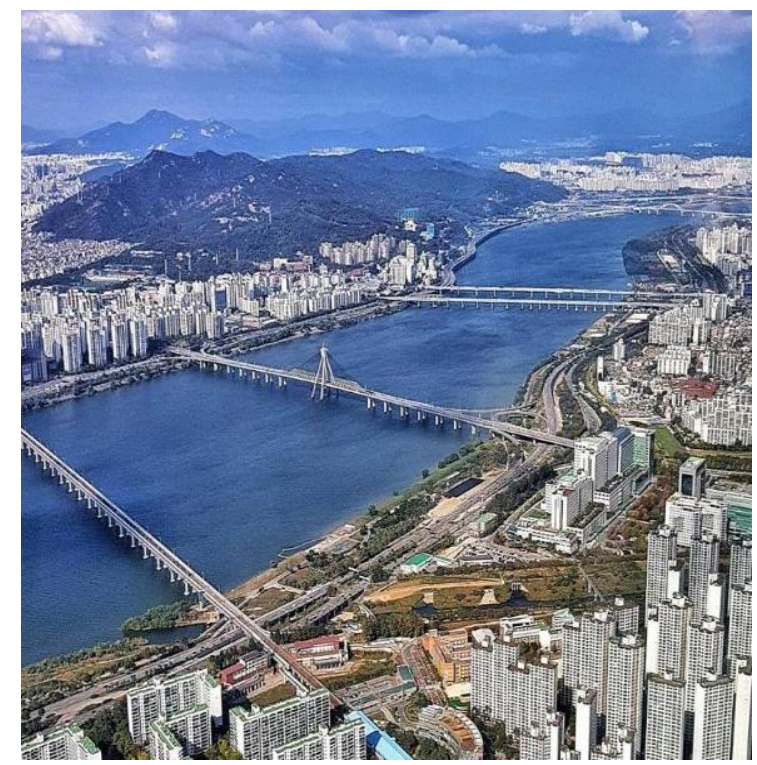

\footnotetext{
${ }^{4}$ Ver imagem 1.

${ }^{5}$ Ver imagem 2.

${ }^{6}$ Ver imagem 2.

${ }^{7}$ Ver imagem 4.

${ }^{8}$ Ver imagens 5
} 


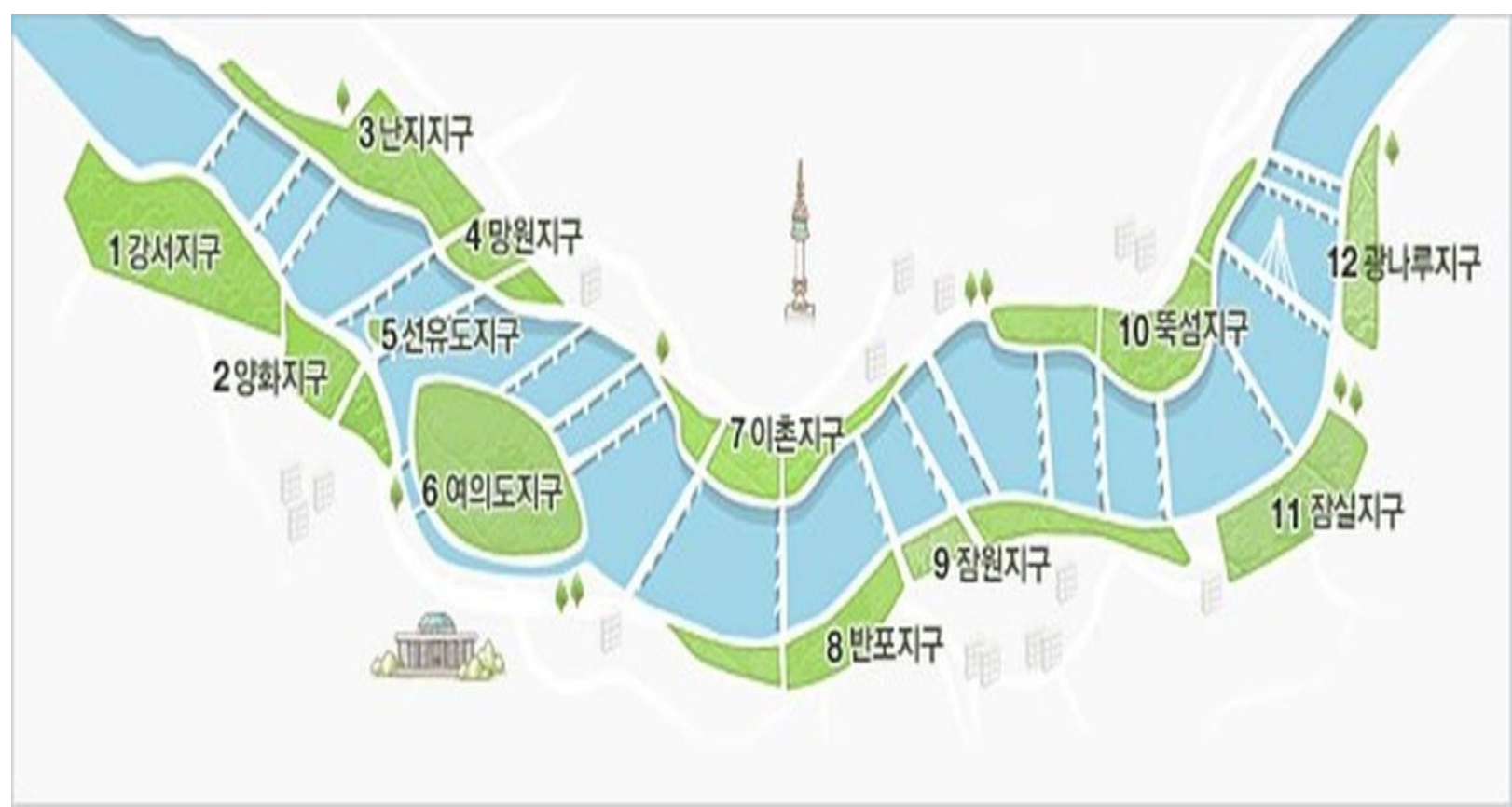

Imagem 02: Rio Han e seus 12 parques. (Fonte: Naver)

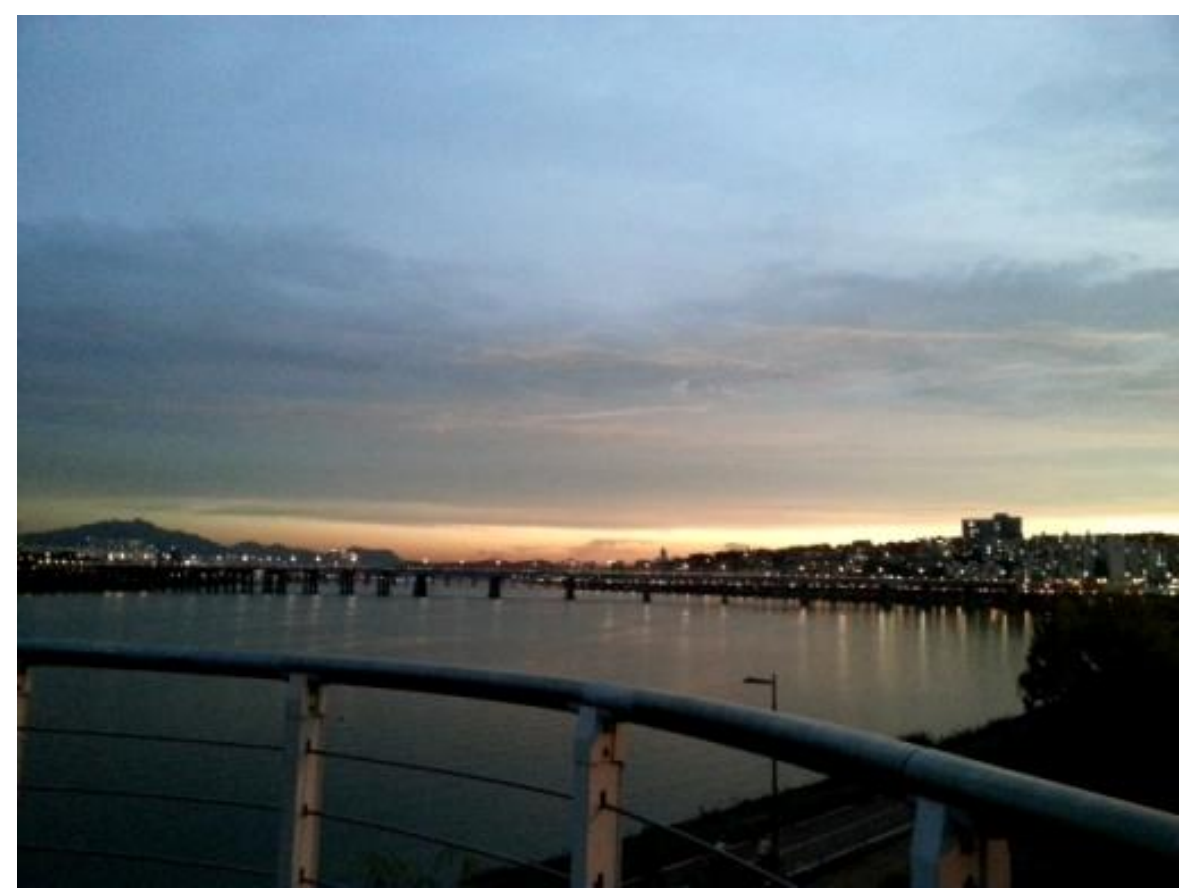

Imagem 3: Meu olhar sobre o Rio Han (Foto: Melissa Rubio dos Santos) 
Imagem 04: Rio Han noturno.

(Fonte: Naver)
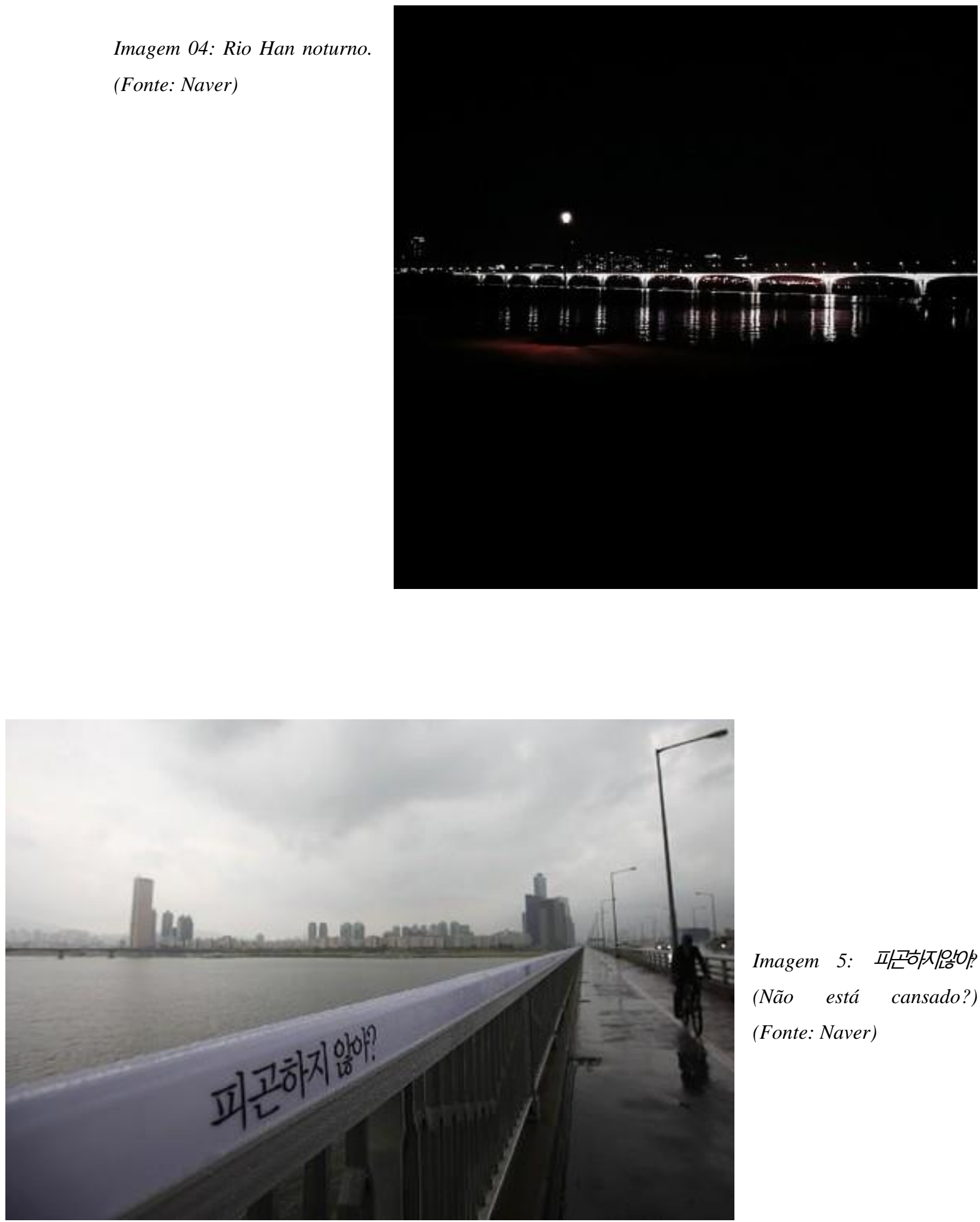

Imagem 5: 프곤하지앟이의

(Não está cansado?)

(Fonte: Naver)

Jangada | nr. 9, jan/dez, 2017 | ISSN 2317-4722 - 57 |P á g i n a 


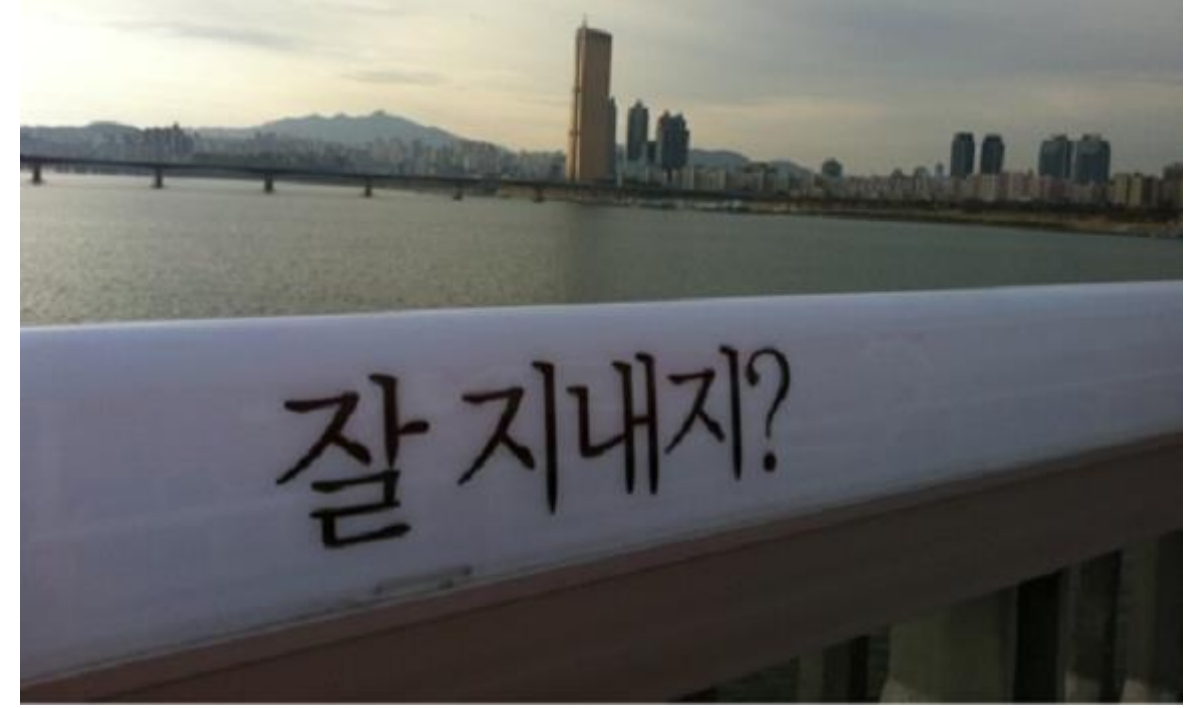

Imagem 6: 잘 지내자? (Como você está?) (Fonte: Naver)

Outro elemento importante para a constelação espacial de Seul são os Portões de Seul. Conta-se na História da Coreia que os portões delimitavam o território da capital do país. Construídos na Dinastia Joseon pelo Rei Taejo, a partir do ano 1396, os portões ${ }^{9}$ ofereceriam proteção máxima contra invasões de inimigos. Utilizando-se da geografia natural formada por muitas montanhas, foram construídas grandes muralhas em torno da cidade no total com oito portas de entrada. ${ }^{10}$ Os quatro maiores portões estavam destinados ao acesso para comércio, relações internas e externas. Esses portões correspondem às localizações norte, sul, leste e oeste da cidade. Sendo eles, então, Namdaemun (남대문)/Sungnyemun ( 숭례문), Dongdaemun (동대문)/ Heunginjimun (흥인지문 ), Sukjeongmun (숙정문)/ Bukdaemun (북대문), Seodaemun (서대문)/ Donuimun (돈의문). Já os quatro outros menores portões estavam destinados ao controle de acesso à cidade dos moradores, soldados, comerciantes e visitantes. Os portões são Dongsomun (동소문), Buksomun (북소문), Namsomun (남소문) e Seosomun (서소문).

\footnotetext{
${ }^{9}$ Ver imagem 7.

${ }^{10}$ Ver imagem 8.
} 


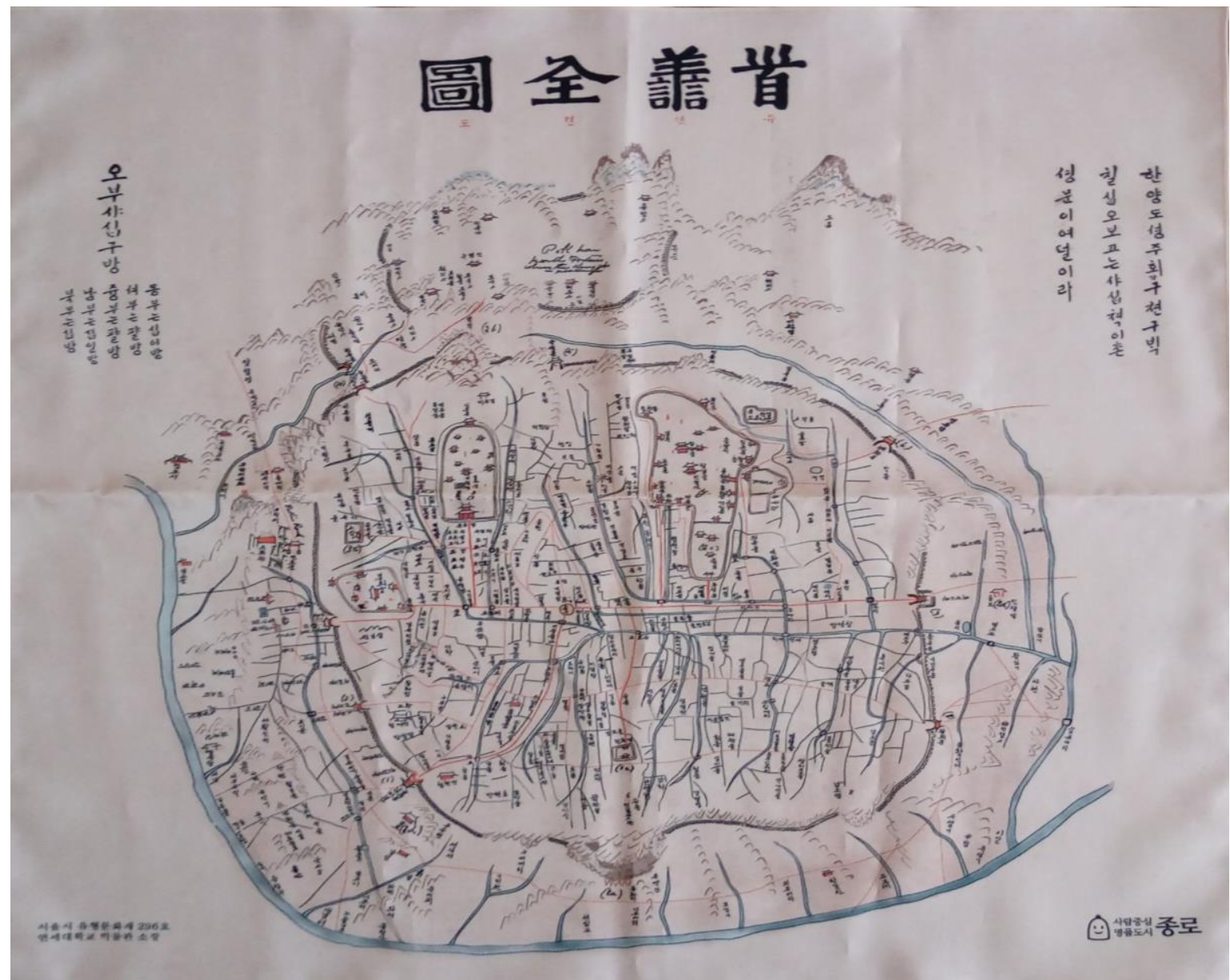

Imagem 07: Mapa antigo de Seul. (Fonte: Jongno -Seoul Metropolitan Government)

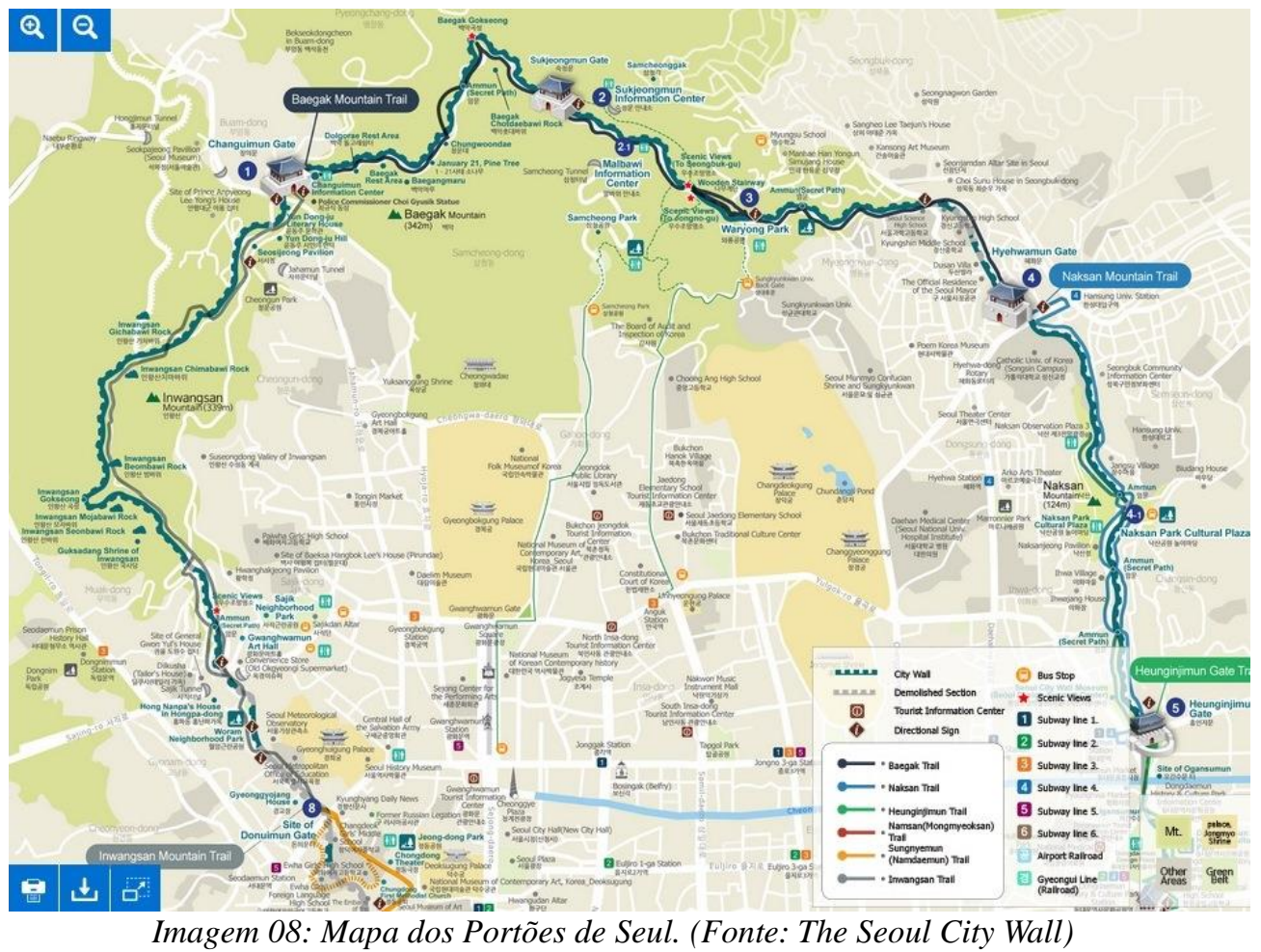

Entretanto, ao passar do tempo, os portões de Seul foram adquirindo novos traços de 


\section{critica | literatura | artes \\ jangada}

significação. Para alguns, os portões são meros lugares históricos para visitação, mas, para outros os portões são lugares estratégicos que orientam visualmente como se fossem um mapa da cidade de Seul. Já, para outros, esses portões denunciam o período obscuro vivido pelos coreanos durante a colonização japonesa no final do século XIX e início do século XX, a qual deixou cicatrizes irreversíveis na história da Coreia. Um exemplo disso é a destruição de palácios, prédios e dos portões de Seul, os quais foram incendiados pelas tropas japonesas.

Sendo assim, os portões que eu visitei em Seul eram apenas projeções, materialidades que tentavam reconstruir as imagens dos portões do passado... Os reais portões já não mais existiam. $^{11}$

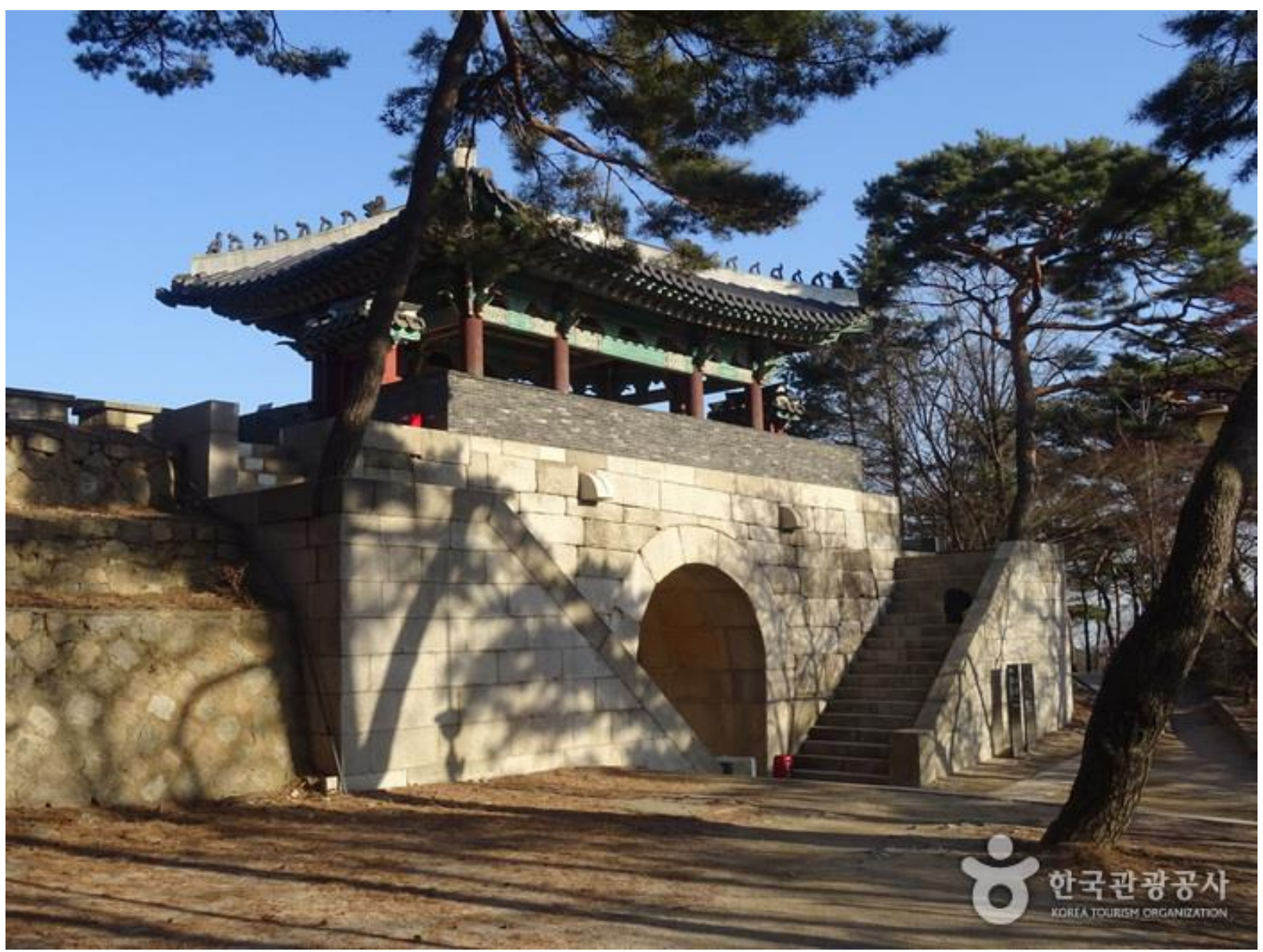

Imagem 09: Portão reconstruído. Portão Sukjeongmun. (Fonte: Korea Tourism Organization)

2. Como se constrói o espaço: Configurações das cidades Incheon e Seul pelo olhar de Park Wan Seo.

${ }^{11}$ Ver imagem 9. 
O romance Mother's Stake I (1980), de Park Wan Seo, conta a história de uma mulher que relembra a sua infância e a sua nova vida na cidade de Seul, sendo um momento que representava uma ruptura com a tradição e a busca por uma nova vida para família. Após a morte repentina do pai, a sua mãe viúva decide deixar para trás a vida tradicional ${ }^{12}$ em uma cidade do interior da Coreia para encontrar oportunidades de mudança e de elevação social da família na capital Seul. Sendo assim, ao acompanhar a mãe e o irmão mais velho, a protagonista que tinha apenas seis anos de idade entra em contato pela primeira vez com a grande cidade. Até então, o mundo para ela não ia além do pequeno e remoto vilarejo em que a protagonista nascera, sendo este um mundo de montanhas familiares...

O deslocamento da família para a cidade que fora planejado pela mãe pode ser visto como uma ruptura com a cultura tradicional coreana. Esta ruptura teve como ponto de partida a separação da família que antes era uninuclear. A mãe tinha um intenso desejo de mudança projetado em seus filhos: seja através da educação formal para que seus filhos pudessem construir uma carreira de destaque e alcançar no futuro boa condição de vida para a família; seja pelo desejo de que sua filha se torne uma New Woman $^{13}$, ou seja, uma mulher de nova geração que rompe com as amarras patriarcais do Neo Confucionismo coreano, conquistando o direito à educação formal e construir uma carreira profissional. Porém, o maior motivação da mãe era transpor a fronteira da cidade: apesar da mudança para Seul, eles não residiam em Seul (região central e nobre), mas sim na região fora dos portões de Seul.

O percurso experenciado pela protagonista é composto por passagens pelas cidades Incheon e Seul. Primeiramente, a protagonista parte do pequeno vilarejo distante em que residia na cidade de Incheon e visita pela primeira vez Songdo (송도), um grande bairro da cidade de Incheon. Ao ouvir as descrições de Songdo, a menina sente-se ameaçada pela imponência da cidade - "They said Songdo was just on the other side of Wardrobe Rocks Hill,the last of four hills between our village and the city, and the steepest. To a six year-old girl who had plodded 20 li, this hill looked as menacing as a towering adult"(PARK, 2016,

\footnotetext{
${ }^{12}$ Seguindo a tradição do Neo Confucionismo vigente na Coreia desde a Dinastia Jeoson, as famílias da Coreia eram uninucleares, ou seja, diferentes gerações residiam na mesma casa. Após o casamento os filhos permaneciam residindo na mesma casa da família do domínio do pai. Já as filhas eram destinadas a conviver no núcleo familiar do marido após o casamento. Caso se torne viúva, a mulher deveria continuar a compor o núcleo da família do marido e a contribuir com os cuidados do ambiente doméstico, dos filhos e dos idosos da família. ${ }^{13}$ New Woman Movement teve início em 1920. Foi o primeiro movimento feminista na Coreia do Sul, sendo protagonizado por escritoras e artistas visuais: Na Hyeseok (Escritora e primeira pintora moderna da Coreia), Myungsoon Kim (primeira romancista moderna da Coreia) e Wonju Kim (Editora da revista Sin Yo Ja (New Women).
} 

p.9 $)^{14}$.

A protagonista, em uma percepção efusiva do bairro urbano Songdo inicia um processo de afecção do espaço diferentemente do que ela tinha no seu vilarejo natal:

This city, the first I had ever seen, looked more dazzling than enormous. It was a mass of lights. To an eye accustomed only to warm, gentle light reflected back from clay walls and tchathed roofs, the midday sunshine had a hostile glint like a shaft of innumerable arrows, broken by the roofs and glass windows of boxy two-story buildings" (PARK, 2016, pp.11-13) ${ }^{15}$.

Deslocar-se entre a vila natal e Songdo é experenciar o movimento entre o "into the city center from the periphery" (p.45). Essa experiência não seria apenas o ato de ver e de conhecer uma cidade, mas também a transformação sofrida pela Coreia — de um país rural para modernização no período em que se passa a narrativa do romance. A ordem urbana é o que mais se destaca nessa experiência de deslocamento da protagonista, conforme pode ser visto na declaraçãoda personagem: “As we approached, the glittering faded and all I saw was urban order. Roads, alleys, stores, and houses were lined up straight as if drawn with a ruler" (PARK, 2016, p. 45).

Para a mãe da protagonista, Songdo jamais poderia ser comparada à grandeza vertiginosa da cidade de Seul. Por exemplo, a estação de Songdo era para ela apenas "a crude copy of Seoul Station”. Entretanto, para a pequena filha, o trânsito entre as cidades era um experienciar de “eventualidades espaço-temporais” (MASSEY, 2008, p. 191).

Now I felt distanced from both of them for the first time in my life, a feeling that could be called loneliness. I wasn't mesmerized by the city because it was so different, as they believed. I felt out of place because of the city's organization and richness. Everyone in good clothes, some even decked out in Western suits, shiny roof tiles, rectangular, two-story houses with glass windows, paved roads with no dit, colorful, unfamiliar objects in stores, loud and lively noises...

Before anybody explained it to me in so many words, my instincts told me that becoming a 'city person' meant being tamed into orderliness, The wildness in me, free to roam for so long, was losing its nerve. (PARK,

\footnotetext{
${ }^{14}$ Conferir tradução no anexo 1.
}

${ }^{15}$ Conferir tradução no anexo 2. 
2016, pp. 47-49). ${ }^{16}$

Songdo Station was the biggest building I'd seen in the city. I was trembling all over, just looking at the dome, the red bricks, the high ceillings, the rails stretching to unknown places, the overpass suspended in the air, and the stairs where everyone was running instead of walking (PARK, 2016, pp. 4749). ${ }^{17}$

Após ter sido afetada pela vida urbana de Songdo, a chegada em Seoul se dá um pouco diferente, pois a protagonista não sente deslumbramento, mas sim medo de se perder da mãe na imensidão da Seoul Station.

It was dusk when we got off at Seoul Station. It was indeed immense, too immense for me to take in the entire scene. I was only concerned about losing sight of Mother in the biggest herd of people I'd ever seen. Mother couldn't hold my hand because she had to carry three bundles, including the one that Grandmother had carried, on her head and in her arms. She didn't like me clinging to her skirt while we climbed up and down the overpasses $\left(\left(\right.\right.$ PARK, 2016, pp. 57-59). ${ }^{18}$

Porém, apesar de estar em Seul, a protagonista constata que o bairro em que sua família iria residir não era nada parecido com a organizada Songdo ou o modelo de vida moderna que era idealizada para a capital do país:

It was a strange neighborhood. Houses as small as country outhouses werw jammed together haphazardly, as if boxes had been tossed out. The first thing I noticed in Songdo was the density of people and the houses, but what overwhelmed me there wasn`t the density itself. I was the order that controlled the city. The order gave density a beauty, overwhelming and yet fascinating to an untamed girl (PARK, 2016, p. 67). ${ }^{19}$

E foi um choque a descoberta de que a mudança para Seul não seria, de fato, realizada.

\footnotetext{
${ }^{16}$ Conferir tradução no anexo 3.

${ }^{17}$ Conferir tradução no anexo 4.

${ }^{18}$ Conferir tradução no anexo 5.

${ }^{19}$ Conferir tradução no anexo 6.
} 


\section{1 jangada}

A família não residiria em Seul, mas sim fora dos portões de Seul. Ainda no início do XX, período que o romance retrata, os portões indicavam quem era cidadão de Seul e quem era de fora. Sendo assim, estabelecia a oposição entre quem era da cidade organizada e da civilização, ou seja, quem era sujeito diferenciado e superior, de quem era do universo rural, sujeitos pertecentes ao mundo arcaico com marcas da Dinastia Joseon. Logo, residir em Hyoencheodong (현처동) era estar além dos portões, o que atribuía à família a imagem de pessoas inferiores, uma vez que não conseguiram fixar-se em local prestigiado de Seul.

'Is this Seoul?' I whined.

'No'. Mother replied unexpectedly, shaking her head resolutely.

I was taken aback by her denial.

'This is outside the gates of Seoul. It's not the real Seoul. We will struggle along here until your brother makes it, and then we will move inside the gates. All right?'

I nodded quickly, even though I couldn't make heads or tails of it, cowered by her vehemence.

When Mother had come to the countryside to get me, she exuded an air of dignity. It had been clear to everyone that she had acquired this new attitude in Seoul. This proud air excused her first escape and made it easy to lure me to Seoul.

So, that proud mother of mine lived outside the gates of Seoul. I had no idea that these areas beyond the gates were officialy part of Seoul, although they were customarily referred to as 'outside the gates'. I took 'outside the gates' literally and sundelly felt like a pauper. I hated Mother for kidnapping me with her wicked sweet talk. I began to miss everything about my country home (PARK, 2016, pp. 67-69). ${ }^{20}$

Para a protagonista, sair de um vilarejo familiar para morar em uma cidade moderna seria motivo de orgulho para a sua mãe. Entretanto, ela descobre que apenas deixara para trás um lugar periférico para permanecem à margem, não ocupando o centro que imaginava ao longo de toda a viagem para Seul... A sua mãe conseguira apenas uma casa fora dos portões de Seul, o que causou intensa revolta para a protagonista quando criança. Entretanto, anos mais tarde a protagonista descobriu que a sua residência fazia parte de Seul apesar de ser nomeada como 'outside the gates' (fora dos portões).

\footnotetext{
${ }^{20}$ Conferir tradução no anexo 7.
} 


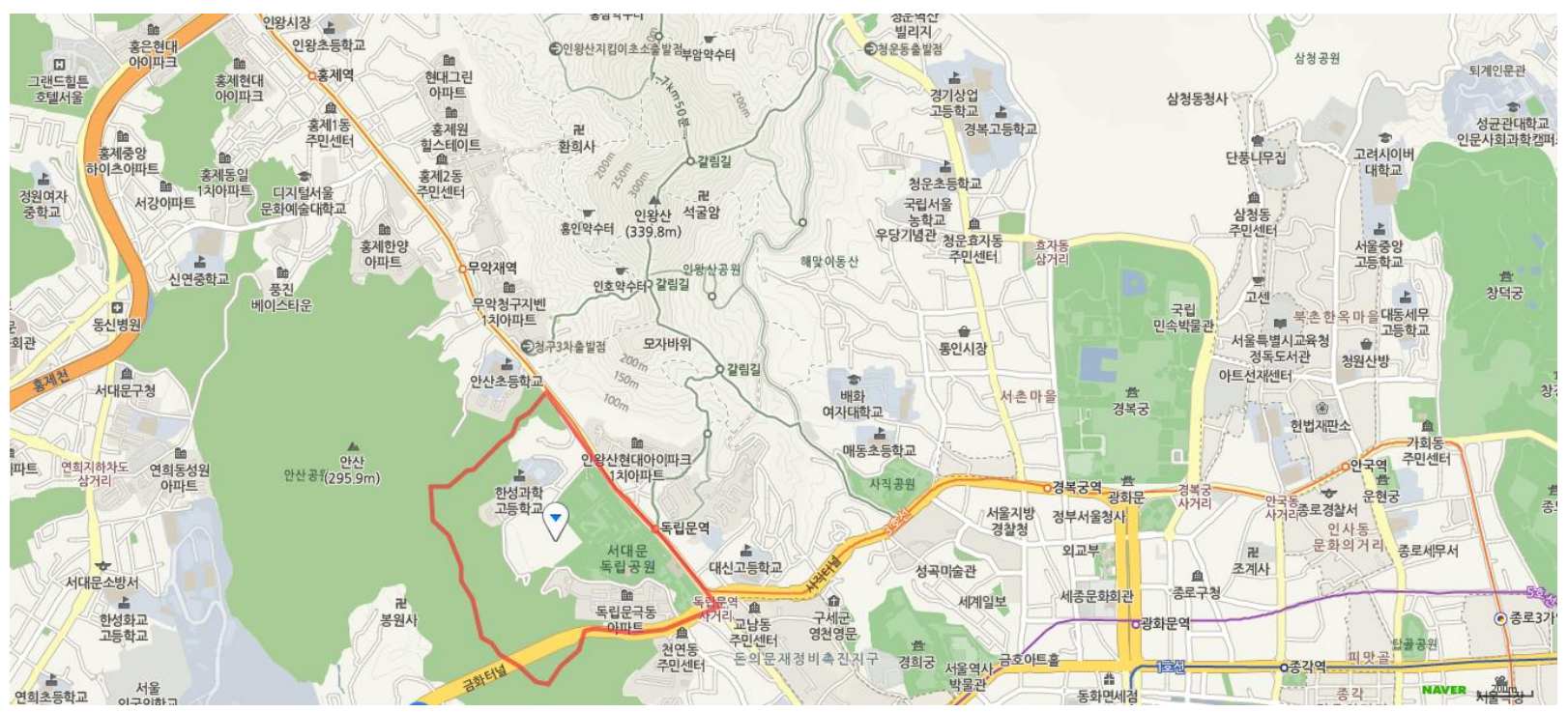

Imagem 10: Mapa de localização do bairro Hyoencheodong (현처동). (Fonte: Naver Map)

Localizada entre as montanhas Ansan e Ingwan, a residência não proporcionava fácil deslocamento para a escola nem para a real Seul, pois as crianças tinham que escalar trilhas na montanha diariamente.

Do you know the name of this mountain?' Brother asked in a kind but reserved voice.

I shook my head.

'It's called Inwang Mountain.'

'Then tigers live here, right?' I asked, remembering a song about roaring tigers on Inwang Mountain from the landslord's radio.

'Not any more. That was a long time ago.'

(...) We climbed until we reached the remmants of the old fortress wall. The city spread out below us.

'Is it inside the gate' from that gate over there? I pointed at the Independence Gate standing tall in the middle of the street. I still needed real gates to understand the concept of 'inside the gates' and 'outside the gates'.

'When are we going to move 'inside the gates?' I wanted Brother to allay the insecurity Mother had instilled in me. I was pretty sure that Brother would reply, 'Soon, When I make it in the world (PARK, 2016, pp. 81-83). ${ }^{21}$

\footnotetext{
${ }^{21}$ Conferir tradução no anexo 9.
} 
A mudança tão esperada para o território dentro do portão Oeste de Seul, demora a se realizar. Apesar dos esforços da mãe e do filho mais velho, a família pôde comprar apenas uma casa no topo de bairro Hyoencheodong (현차동), bairro este em que já tinham alugado uma pequena casa.

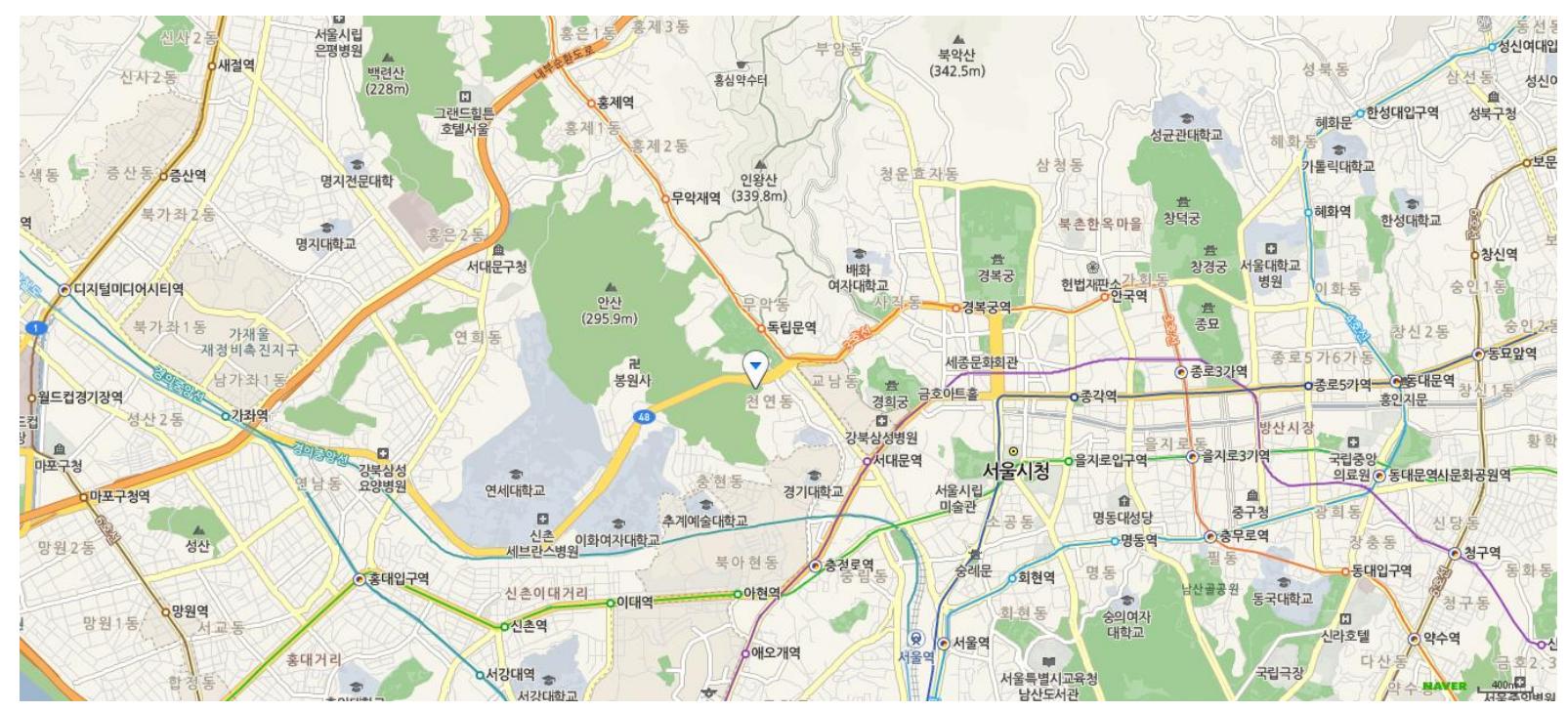

Imagem 11: Mapa de localização do bairro Yeongcheondong ( 천연동). (Fonte: Naver Map)

Anos após, a família se muda finalmente para o bairro Yeongcheondong (영천동). Para a mãe, morar 'dentro do portão' é uma questão de estabelecer o ponto decisivo e final de conquista na cidade de Seul. Residir dentro dos portões de Seul seria deixar a estaca que dá título ao nome do romance, Mother's Stake I. A escolha da cidade de Seul como o lugar para construir uma nova vida de ruptura(s) das amarras da tradição, o lugar que proporcionou ressignificações e descobertas através dos deslocamentos vivenciados nos arredores de Seul e dos deslocamentos traçados para aproximar a família para dentro dos portões de Seul. Todos estes são elementos importantes para ver as distintas eventualidades-temporais vivenciadas pela família e por cada personagem na cidade de Seul.

I wanted to walk the path I had takes to school so long ago. To me the hill had been my commuting route, but to Mother it had been a fortress separating 'inside the gates' from 'outside the gates'. Now it was simply a green patch in the middle of the city. When I arrived at the point leading down to the valley, I was stopped by a fortress wall. This newly built wall 


\section{1. canganda}

came down from Inwang Mountain toward West Gate, and had a small opening in the middle. Now, vividly before me, was concrete evidence of 'inside' and 'outside' sthe gates. Who would have imagined in the old days that I would experience this division as concretely as I did now? (PARK, 2016, p. 175) $)^{22}$

\section{Lugares de Seul, constelações espaciais.}

Após a discussão tecida neste artigo, considero importante trazer algumas questões: 1. Eu, uma pesquisadora brasileira de Estudos Coreanos, poderia experenciar e ressignificar os espaços e os lugares da Coreia? 2. Haveria uma forma de ler os elementos das constelações espaciais de Seul que seja transgressora aos discursos e aos olhares dos livros de história que eu lera no passado? 3. Como as obras de autoria feminina subvertem a história que tende a fixar o espaço? Somente ao ler as imagens do Rio Han e dos Portões de Seul como lugares que expressam diversas temporalidades, sim, será possível construir a minha própria leitura das imagens da cidade de Seul, a minha leitura desviante. Uma vez que eu compreendo 'lugar' como um "tecer de estórias em processo" (MASSEY, p. 191). Ou seja, ver ou ler o lugar como uma "constelação particular" e, acima de tudo, considerando-o "em processo, uma tarefa inacabada" (2008, p. 191). Na obra de Park Wan Seo foi possível constatar que através das relações estabelecidas com os novos lugares os personagens mostram os lugares "não como pontos ou áreas em mapas, mas como integrações de espaço e tempo" (MASSEY, 2008, p. 191). Acerca do espaço cabe destacar a impossibilidade de fixidez para esta categoria ou conceito, pois o significado e efeito são constantemente transgredidos pelos seres que transitam e habitam o espaço. Conforme foi discutido ao longo do texto, os lugares de Seul aqui apresentados possuem diferentes processos de significação ao serem mediados por diversas temporalidades e também pelas relações que eles estabelecem com os seres humanos (ou ficcionais) que os olham. Portanto, dessa forma, o Rio Han não é um lugar com imagem e significados imutáveis, assim como os portões se configuram não como lugar fixo, mas sim lugares múltiplos e deslizantes lugar(es) da cidade de Seul.

\section{RDEEFRÊNCIAS BIBLIOGRÁFICAS}

${ }^{22}$ Conferir tradução no anexo 10. 
EPSTEIN, Stephen J. Prefácio. In: Montgomey, Charles. Three Days in That Autumn by Pak Wanseo. 21 de outubro de 2009. Disponível em: 〈http://www.ktlit.com/three-days-in-that-autumn-by-pakwanseo/>

Acesso em 19 jan. 2017.

FRANCO, Jean. Marcar diferenças, cruzar fronteiras. Traduzido por Alai Garcia Diniz. Florianópolis: Editora Mulheres, 2005.

FULTON, Bruce. Modern Korean Fiction: An Anthology New York: Columbia University Press, 2005, $408 \mathrm{p}$.

Kids Fun in Seoul. Disponível em: 〈https://kidsfuninseoul.wordpress.com/learning-fun/city-walks/> Acessado em 06 fev.2017.

KIM, Yeung- Hee. Traditions in Modern Korean Women's Fiction Writing. Questioning Minds: Short Stories by Modern Korean Women Writers. Honolulu, HI, USA: University of Hawaii Press, 2010.

$\mathrm{KOH}$, Helen. "Discussing the development of the female writer in Korea". In: Korean Literature In Translation. Disponível em: <http://www.ktlit.com/women-and-korean-literature-short-article-byhelen-koh/> Acesso em: 15 jan. 2017.

"Women and literature". Anais GTK Korean Studies. Korean Literature Translation Institute Disponível em: 〈http://klti.or.kr/main.do/> Acesso em: 15 jan. 2016.

KWON, Insook. "The New Women's Movement" in 1920s Korea: Rethinking the Relationship Between Imperialism and Women'. In: Gender \& History, Vol.10 No.3 November 1998, pp. 381-405.

Korea Award. Disponível em:<http://www.koreaaward.com/kor/> Acessado em 06/02/2017.

MASSEY, Doreen. Pelo Espaço. Traduzido por Hilda Pareto Maciel; Rogério Haesbaert. Rio de Janeiro: Bertrand Brasil, 2008.

Naver. Disponível em: $<$ http://www.naver.com/> Acessado em 16/03/2017.

PARK, Wan Seo. Mother's Stake I. Traduzido por Yoo Young-nan. Paju: Asia Publishers, 2016. Edição bilíngue Coreano- Inglês, 206 pp.

Visit Seoul Net Disponível em: $\lfloor$ http://english.visitseoul.net/index > Acessado em 02/02/2017.

YOO, Jung Suk. "Characteristics of Feminine Writing in 1990s Korean Women's Novels: Women's Autobiographical and Confessional Writing. "'In: The Review of Korean Studies, Volume 11 Number 2 (June 2008), pp. 97-115.

\section{ANEXOS}

Traduções de excertos The Mother's Stake (Eommanui Malttuk, 1980), de Park Wan Seo, citados no artigo:

1. "Elas disseram que Songdo estava do outro lado do Wardrobe Rocks Hill, a última das quatro colinas entre nossa aldeia e a cidade, e o mais íngreme. Para uma menina de seis anos que tinha arrastado 20 li, esta colina parecia tão ameaçadora como um grande adulto." (PARK, 2016, pp. 9). (Tradução minha)

2. "Esta cidade, a primeira que eu já tinha visto, parecia mais deslumbrante do que enorme. 
Era uma massa de luzes. Para um olho acostumado apenas à luz morna e suave refletida para trás das paredes de argila e tchathed telhados, o sol do meio dia tinha um brilho hostil como um eixo de inúmeras flechas, quebrado pelos telhados e janelas de vidro de edifícios de dois andares." (PARK, 2016, pp. 11-13). (Tradução minha)

3. "À medida que nos aproximávamos, o brilho desbotado e tudo o que via era ordem urbana. Estradas, becos, lojas e casas estavam alinhados em linha reta como se estivessem desenhados com uma régua." (PARK, 2016, pp. 45). (Tradução minha)

4. "Agora me senti distanciada de ambas pela primeira vez na minha vida, um sentimento que poderia ser chamado de solidão. Eu não estava hipnotizada pela cidade porque era tão diferente, como elas acreditavam. Senti-me deslocada devido à organização e riqueza da cidade. Todos em boas roupas, alguns até vestidos em ternos ocidentais, telhas brilhantes, retangulares, casas de dois andares com janelas de vidro, estradas pavimentadas sem dizer, objetos coloridos e desconhecidos nas lojas, barulhos altos e vivos ...

Antes que alguém me explicasse isso em tantas palavras, meus instintos me disseram que tornar-se uma "pessoa da cidade" significava ser domesticado em ordem, a selvageria em mim, livre para vagar por tanto tempo, estava perdendo sua coragem." (PARK, 2016, pp. 4749). (Tradução minha)

5. "A estação de Songdo era o maior edifício que eu tinha visto na cidade. Eu estava tremendo por todo corpo, apenas olhando para a cúpula, os tijolos vermelhos, os altos tetos, os trilhos que se estendiam para lugares desconhecidos, o viaduto suspenso no ar e as escadas onde todo mundo corria em vez de andar.” (PARK, 2016, pp. 47-49). (Tradução minha)

6. "Estava anoitecendo quando chegamos na estação de Seul. Era realmente imenso, demasiado imenso para mim para assimilar toda a cena. Eu só estava preocupada em não perder de vista a mãe no maior rebanho de pessoas que eu já tinha visto. Mamãe não podia segurar minha mão porque tinha que carregar três pacotes, incluindo o que a avó levara, na cabeça e nos braços. Ela não gostava que eu me agarrava à saia enquanto subíamos e descíamos os viadutos.” (PARK, 2016, pp. 57-59). (Tradução minha)

7. "Era um bairro estranho. Casas como pequenas casas de campo estavam juntas ao acaso, como se caixas tivessem sido jogadas para fora. A primeira coisa que eu notei em Songdo foi 


\section{crtica | literatura | arte \\ jangada}

a densidade de pessoas e as casas, mas o que me dominou lá não era a densidade em si. Eu era a ordem que controlava a cidade. A ordem deu à densidade uma beleza, esmagadora e ainda fascinante para uma menina indomada" (PARK, 2016, p. 67). (Tradução minha)

8. “-É Seul? Eu lamuriava.

— 'Não'. Mãe respondeu inesperadamente, balançando a cabeça resolutamente.

Fiquei surpresa com sua negação.

— Isto é fora dos portões de Seul. Não é a verdadeira Seul. Vamos lutar por aqui até que seu irmão o faça, e então vamos nos mudar para dentro dos portões. Tudo bem?

Eu concordei rapidamente, mesmo que eu não pudesse discernir nada, encolhida por sua veemência.

Quando minha Mãe veio ao campo para me buscar, ela exalava um ar de dignidade. Tinha sido claro para todos que ela tinha adquirido essa nova atitude em Seul. Este ar orgulhoso justificou sua primeira fuga e tornou mais fácil para me atrair para Seul. Então, aquela orgulhosa mãe vivia fora dos portões de Seul. Eu não tinha idéia de que essas áreas além dos portões eram oficialmente parte de Seul, embora eles fossem habitualmente referidos como 'fora dos portões'. Eu compreendi 'fora dos portões' literalmente e de repente me senti como um mendigo. Eu odiava a Mãe por me ter sequestrado com sua doce conversa. Comecei a sentir falta de tudo na minha casa do campo.” (PARK, 2016, pp. 67-69). (Tradução minha)

9. "— Você sabe o nome dessa montanha? - perguntou meu irmão em voz amável, mas reservada.

Eu balancei a cabeça.

- Chama-se Montanha Inwang.

— Então tigres vivem aqui, né? Eu perguntei lembrando-me de uma canção sobre o rugir tigres na montanha de Inwang do rádio do dono da casa.

'Não mais. Isso foi há muito tempo atrás.'(...) Subimos até chegarmos aos restos da antiga muralha da fortaleza. A cidade se espalhou abaixo de nós.

— 'Está dentro do portão', daquele portão ali? Apontei para o Portão da Independência erguido no meio da rua. Eu ainda precisava de portões reais para entender o conceito de 'dentro dos portões' e 'fora dos portões'.

- Quando vamos nos mudar para dentro dos portões? Eu queria que o meu irmão aliviasse a insegurança que a Mãe tinha inculcado em mim. Eu tinha certeza de que o irmão iria responder: 'Logo, quando eu me tornar uma pessoa no mundo'. " (PARK, 2016, pp. 81- 
83). (Tradução minha)

10. "Eu queria percorrer o caminho que eu fazia para a escola há muito tempo. Para mim a colina tinha sido a minha rota de deslocamento, mas para a mãe tinha sido uma fortaleza separando 'dentro dos portões' de 'fora dos portões'. Agora era simplesmente um retalho verde no meio da cidade. Quando cheguei ao ponto que levava ao vale, fui parada por uma muralha de fortaleza. Esta parede recentemente construída desceu de Inwang Mountain em direção ao Portão do Oeste e tinha uma pequena abertura no meio. Agora, vividamente diante de mim, havia uma prova concreta de 'dentro' e 'fora' dos portões. Quem teria imaginado nos velhos tempos que eu iria experimentar esta divisão tão concretamente como eu fiz agora?" (PARK, 2016, p. 175). (Tradução minha) 